Article

\title{
An Efficient Strategy for the Fabrication of CuS as a Highly Excellent and Recyclable Photocatalyst for the Degradation of Organic Dyes
}

\author{
Na Qin, Wutao Wei, Chao Huang and Liwei Mi * \\ Center for Advanced Materials Research, Zhongyuan University of Technology, Zhengzhou 450007, China; \\ qina@zut.edu.cn (N.Q.); weiwutaozut@zut.edu.cn (W.W.); huangchao@zut.edu.cn (C.H.) \\ * Correspondence: mlwzzu@163.com
}

Received: 20 November 2019; Accepted: 27 December 2019; Published: 30 December 2019

\begin{abstract}
An effective and practical in situ sulfuration approach has been developed in this work, for the fabrication of CuS with a 3D hierarchical network structure under mild preparation conditions. The prepared CuS consists of a primary structure of the multi-structure interchange copper foam precursor, and a secondary structure of nanoplates. The structural characteristics, morphologies, and photocatalytic performances of the prepared photocatalyst were investigated systematically. To evaluate the photocatalytic performance of the prepared CuS samples, we investigated the degradation of $\mathrm{MB}$ (methylene blue), $\mathrm{RhB}$ (Rhodamine $\mathrm{B}$ ), and $\mathrm{MB} / \mathrm{RhB}$ dye solutions over the samples under the irradiation of simulated solar light. Specifically, the degradation of RhB rapidly reached $\approx 100.0 \%$ after simulated solar light irradiation for $25 \mathrm{~min}$, which is higher than those of P25 (83.0\%) and bulk $\mathrm{CuS}$ (54.8\%). For the mixed systems of $\mathrm{MB} / \mathrm{RhB}$, both the degradations of $\mathrm{MB}$ and $\mathrm{RhB}$ reached up to $\approx 99.0 \%$ after simulated solar light irradiation for $25 \mathrm{~min}$. The superior photocatalytic performances of the prepared samples are attributed to the synergistic effects of high optical absorption, large specific surface area, and abundant active sites. The prepared catalysts can retain the photocatalytic activities during the entire reaction process without significant loss after four catalytic cycles, which reveals that the $\mathrm{CuS}$ with a stable 3D hierarchical network structure has a promising prospect as an ideal recyclable catalyst.
\end{abstract}

Keywords: CuS; photocatalysis; simulated solar light; organic dyes

\section{Introduction}

Owing to the energy crisis and environmental pollution issues, photocatalytic treatment, one of the most efficient, environmentally safe, and promising methods for eliminating organic and harmful pollutants in water, has attracted considerable research interest. Sunlight is a non-polluting and easy-to-access energy source, with great potential to drive environmentally friendly organic transformations [1]. In particular, the irradiation of light is essential for the photocatalysis reaction, involving the advanced oxidation process (AOP). AOP is based on hydroxyl radicals $(\mathrm{OH} \cdot)$ produced by the combination of catalysts and irradiation, sometimes together with oxidants, to convert organic and harmful pollutants into small molecules (e.g., $\mathrm{CO}_{2}, \mathrm{H}_{2} \mathrm{O}$ ) via Fenton, photo-Fenton reactions, and photocatalysis [2,3]. In particular, for the photo-Fenton reactions, the $\mathrm{H}_{2} \mathrm{O}_{2}$ serves as an efficient scavenger that can capture the photo-generated electrons to form more $\mathrm{OH} \cdot$; thus, a certain amount of $\mathrm{H}_{2} \mathrm{O}_{2}$ is necessary. As one of the most well-known photocatalysts, $\mathrm{TiO}_{2}$ has been extensively used for the efficient degradation of organic pollutants [4-7]. However, the wide bandgap of $\mathrm{TiO}_{2}$ enables the absorption of ultraviolet light only, which considerably inhibits the generation of hydroxyl free radicals that are critical in the oxidation of organic pollutants, resulting in relatively low efficiency in 
solar energy utilization [8-12]. Therefore, the development of photocatalysts with high hydroxyl free radical generation rates is desirable for the enhancement of photocatalytic performance.

Various semiconductors with narrow bandgaps have been developed to improve the photocatalytic efficiency [13-16]. Among them, copper sulfide (CuS), with a bandgap of $\approx 2.0 \mathrm{eV}$, has excellent optical and electrical properties with a wide range of applications in photocatalysis [17-22], which is considered as an attractive and important photocatalyst for dye degradation due to nontoxicity availability, and stability under ambient conditions $[23,24]$. Previous studies have shown that different morphologies of CuS can significantly impact their properties, as well as their potential applications. Compared with bulk CuS, microstructure CuS displays improved photo-electric properties and catalytic activities, enhanced electric conductivity, and capacitance owing to its small particle size and large specific energy density [25]. Recently, 1D, 2D, and 3D CuS micro/nanostructures with various morphologies, such as micro/nano-wire, sheet, and hierarchical structures have been fabricated. According to the report, nanowires [26-28] and nanosheets [29-31] have been used as building blocks for manufacturing micro/nanostructured materials with 3D hierarchical morphologies. On the basis of the 1D single nanowire or 2D nanosheet structure, 3D hierarchical structure materials afford more ion transmission paths and a stable structure, which have received increasing research attention because their 3D hierarchical structure features a large surface area and abundant surface active sites [32,33]. Therefore, research on the degradation of dye with 3D hierarchical structure CuS has attracted much attention. Over decades of research, various protocols have been developed for the fabrication of CuS with a 3D hierarchical structure, such as the sacrificial templating in the solvothermal process [34,35]. Nevertheless, the synthesis of 3D hierarchical structured materials through a one-step in situ heating sulfuration method is seldom reported. In the process of heating sulfuration, the copper foam is more effectively contacted with $\mathrm{S}$ to realize a one-step reaction. The heating sulfuration method is simple, low-cost, and tractable. Consequently, a straightforward and efficient one-step in situ heating sulfuration treatment is developed for the fabrication of $\mathrm{CuS}$ with a 3D hierarchical structure.

Herein, we prepared CuS with a 3D hierarchical network structure using a one-step in situ heating sulfuration approach. To evaluate the photocatalytic performance of the prepared CuS, we investigated the degradation of $\mathrm{MB}$ (methylene blue), $\mathrm{RhB}$ (Rhodamine $\mathrm{B}$ ), and $\mathrm{MB} / \mathrm{RhB}$ dye solutions under the irradiation of simulated solar light.

\section{Results}

\subsection{Characterizations}

Figure 1a shows the XRD pattern of the prepared $\mathrm{CuS}$, which demonstrates that all diffraction peaks are in good agreement with the hexagonal CuS phase (JCPDS No. 06-0464) [20,36]. Characteristic peaks of other phases were not detected, suggesting that the copper foam completely converted into the highly pure CuS sample after the sulfuration reaction. The UV-vis spectrum of the prepared $\mathrm{CuS}$ was provided. As can be seen from Figure $1 \mathrm{~b}, \mathrm{CuS}$ displays a prominent photoabsorption ability, suggesting that it has the potential to be an efficient photocatalyst under simulated solar light irradiation. The bandgap energy of $\mathrm{CuS}$ was found to be $1.58 \mathrm{eV}$ by using the Tauc plot approach $[37,38]$. The nitrogen adsorption-desorption isotherms of the prepared CuS are provided in Figure S1 (Supplementary Material). The BET surface area of the prepared CuS $\left(12.06 \mathrm{~cm}^{2} \mathrm{~g}^{-1}\right)$ was larger than those of other reported CuS microflowers $\left(7.93 \mathrm{~cm}^{2} \mathrm{~g}^{-1}\right)$, spheres $\left(3.16 \mathrm{~cm}^{2} \mathrm{~g}^{-1}\right)$, and multiplates $\left(6.94 \mathrm{~cm}^{2} \mathrm{~g}^{-1}\right)$ [25], indicating that it can provide more active sites for reaction. 

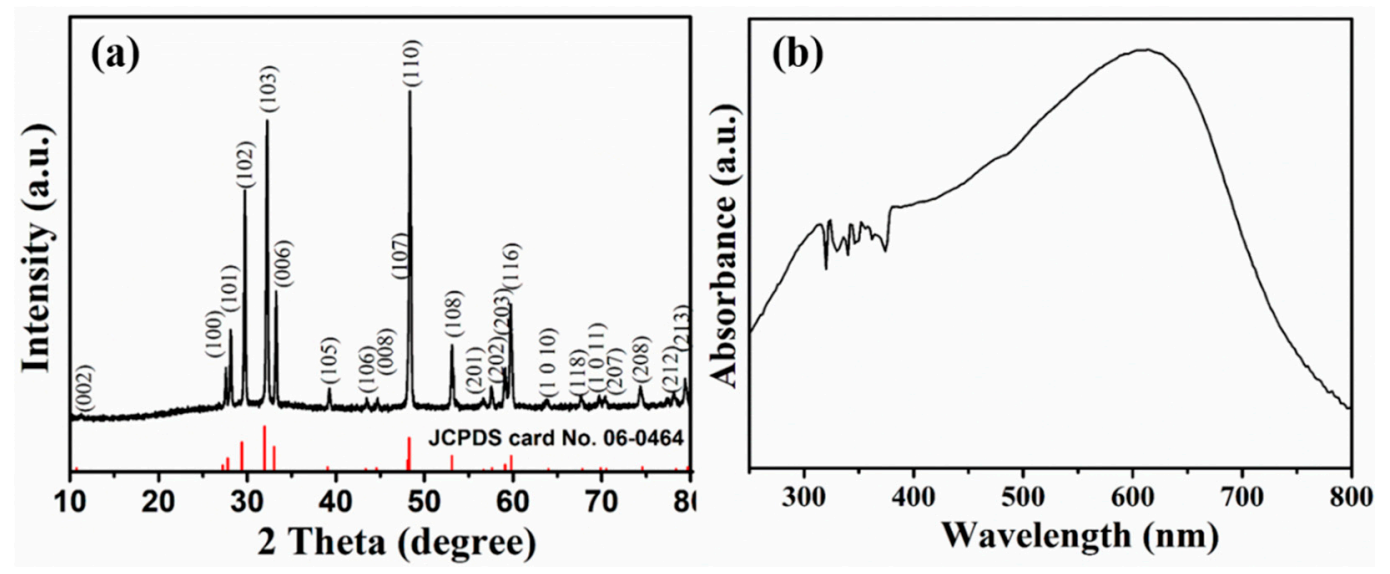

Figure 1. (a) XRD pattern and (b) UV-vis spectra of the prepared CuS.

The morphologies of the prepared samples were also analyzed by SEM and TEM. As can be seen from Figure 2a, after one-step in situ heating sulfuration, CuS samples grew on the copper foam and maintained the characteristic structure of the copper foam (the SEM image of the original copper foam is shown in Figure S2 in Supplementary Material). Compared with Figure 2a, Figure 2b clearly shows that $\mathrm{CUS}$ nanoplates are formed on the copper foam to afford the 3D hierarchical CuS network structure, indicating that it can provide sufficient reaction active sites. As shown in the EDS spectrum of Figure 2c, the prepared samples only consisted of $\mathrm{Cu}$ and $\mathrm{S}$ elements. The atomic ratio of $\mathrm{Cu}$ to $\mathrm{S}$ in the copper sulfide was close to one. The HRTEM image in Figure 2d reveals that the lattice fringes of $0.30 \mathrm{~nm}$ can be attributed to the (102) lattice plane of CuS. To further confirm the chemical composition and the valence state on the surface of the sample, we conducted the XPS analysis.
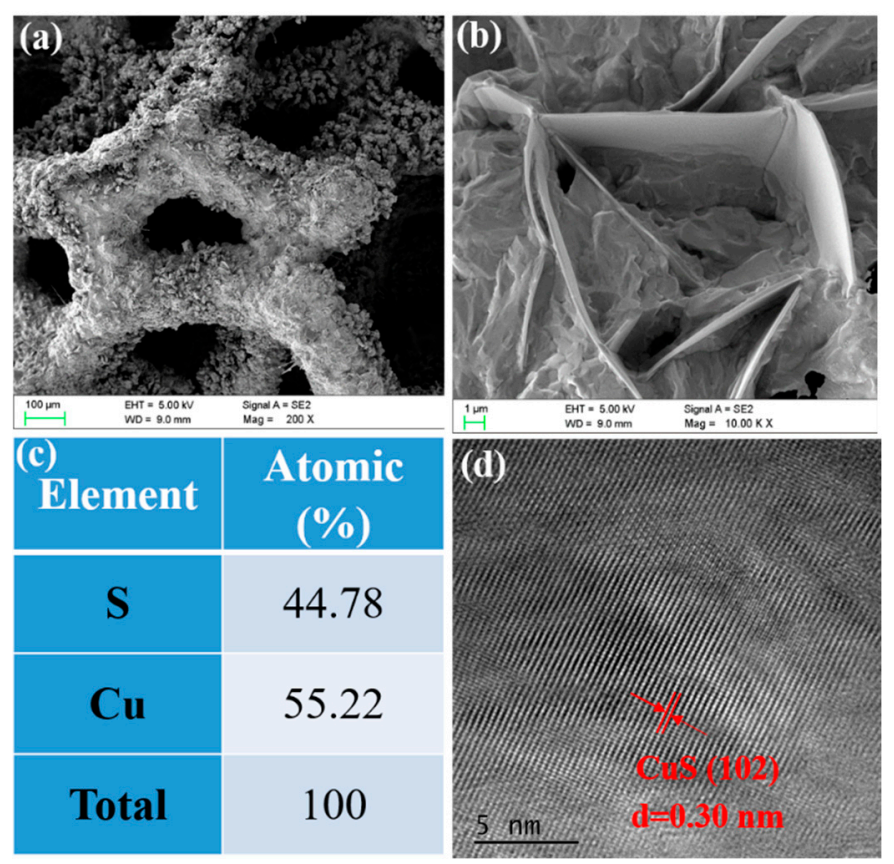

Figure 2. Characterization of CUS morphology: (a,b) SEM images in low and high magnification, (c) EDS results, (d) HRTEM image.

As shown in Figure 3a, the binding energies of $\mathrm{Cu} 2 \mathrm{p}_{3 / 2}$ and $\mathrm{Cu} 2 \mathrm{p}_{1 / 2}$ peaks are at 932.1 and $952.1 \mathrm{eV}$, respectively, which belong to $\mathrm{Cu}^{2+}$ in $\mathrm{CuS}$ [39-43]. In addition, two shakeup lines at 943.2 and $963.6 \mathrm{eV}$ were observed, corresponding to the satellite peaks of $\mathrm{Cu}^{2+}[42,43]$. Furthermore, the symmetrical shapes of two $\mathrm{Cu} 2 \mathrm{p}$ XPS peaks also confirm the presence of pure CuS. The peaks 
at 162.2 and $163.3 \mathrm{eV}$ (Figure $3 \mathrm{~b}$ ) are characteristic of the $\mathrm{S}^{2-}$, which corresponds to $S 2 \mathrm{p}_{3 / 2}$ and $2 \mathrm{p}_{1 / 2}$, respectively [43]. In summary, these results demonstrate that the prepared sample is of pure CuS, which is consistent with its XRD pattern.
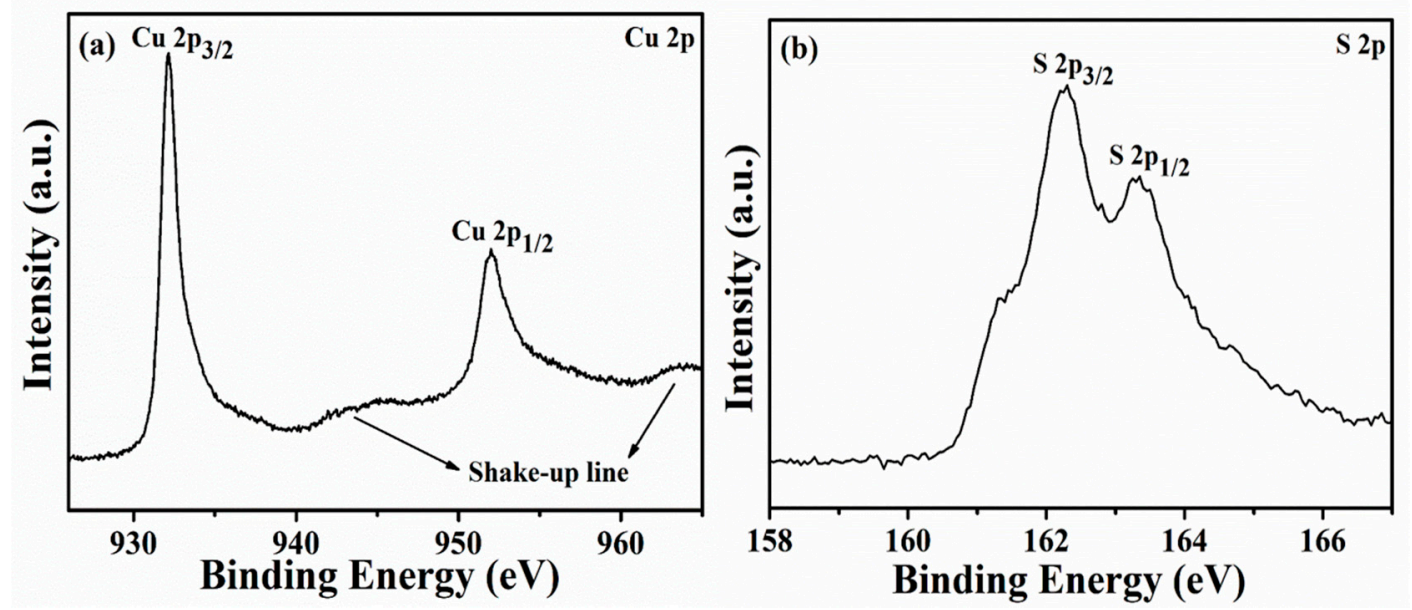

Figure 3. XPS spectra of CuS: (a) Cu 2p, (b) S 2p.

\subsection{Photocatalytic Performance}

To evaluate the photocatalytic performance of the prepared sample, we have investigated the degradation of $\mathrm{MB}, \mathrm{RhB}$, and $\mathrm{MB} / \mathrm{RhB}$ dye solutions over the samples under simulated solar light irradiation. As shown in Figure $4 \mathrm{a}, \mathrm{b}$, it can be seen that the degradation of dye is negligible without light or $\mathrm{H}_{2} \mathrm{O}_{2}$. When a small amount of $\mathrm{H}_{2} \mathrm{O}_{2}$ was added (without catalyst), the degradation efficiency was slightly improved, possibly due to the photolysis of $\mathrm{H}_{2} \mathrm{O}_{2}$ triggered by incident light. Notably, $\mathrm{CuS}$ was highly active when adding $\mathrm{H}_{2} \mathrm{O}_{2}$ (as shown in Figure S3a). As a result, the degradation of $\mathrm{RhB}$ rapidly increased to $\approx 100.0 \%$ after simulated solar light irradiation for $25 \mathrm{~min}$, which is higher than those of P25 (83.0\%) and bulk CuS (54.8\%) under identical experimental conditions. In addition, the degradation of MB rapidly increased to $\approx 100.0 \%$ after simulated solar light irradiation for $25 \mathrm{~min}$, which is also more effective than that of bulk CuS (as shown in Figure S3b). To further reveal the photocatalytic efficiencies of samples, the kinetic rate constants were measured. As shown in Figure 4c, the kinetic rate constants for degradation of $\mathrm{RhB}$ follow the order of: $\mathrm{CuS}+\mathrm{H}_{2} \mathrm{O}_{2}\left(0.11 \mathrm{~min}^{-1}\right)>$ $\mathrm{P} 25+\mathrm{H}_{2} \mathrm{O}_{2}\left(0.065 \mathrm{~min}^{-1}\right)>$ bulk CuS $+\mathrm{H}_{2} \mathrm{O}_{2}\left(0.036 \mathrm{~min}^{-1}\right)>$ No catalyst $+\mathrm{H}_{2} \mathrm{O}_{2}\left(0.0045 \mathrm{~min}^{-1}\right)>$ dark $\left(0.0021 \mathrm{~min}^{-1}\right)>\mathrm{CuS}\left(0.0019 \mathrm{~min}^{-1}\right)$, suggesting the high efficiency of the prepared CuS under simulated solar light irradiation. Figure $4 \mathrm{~d}$ is the kinetics of $\mathrm{MB}$ photocatalytic degradation over different photocatalysts, based on the data plotted in Figure $4 \mathrm{~b}$. It is obvious that the prepared CuS exhibits superior photocatalytic performance. For $\mathrm{CuS}+\mathrm{H}_{2} \mathrm{O}_{2}$, as seen in Figure $4 \mathrm{c}$, d, the relationships between $\ln \left(\mathrm{C}_{0} / \mathrm{C}_{\mathrm{t}}\right)$ and irradiation time were not linear, as they were for the reaction systems maintained at $30^{\circ} \mathrm{C}$, and the slopes seemed to increase gradually. The continuous increase in the temperature of the reaction systems was most likely the cause of the observed phenomena, which are similar to those reported in previous literature [44]. Furthermore, to better understand the photocatalytic activity of $\mathrm{CuS}$, a coexisted model system is simulated using $\mathrm{MB}$ and $\mathrm{RhB}$ under the same conditions, to degrade the single dye solutions ( $0.05 \mathrm{~g}$ of photocatalyst, $40 \mathrm{~mL}$ of $10 \mathrm{mg} \mathrm{L}^{-1} \mathrm{MB} / \mathrm{RhB}, 40 \mu \mathrm{L}$ of $\mathrm{H}_{2} \mathrm{O}_{2}, \mathrm{pH} 4$, $30{ }^{\circ} \mathrm{C}$.). As displayed in Figure $4 \mathrm{e}$, it can be seen that, for the mixed systems of MB/RhB, both the degradation of $\mathrm{MB}$ and $\mathrm{RhB}$ reached up to $\approx 99.0 \%$ after simulated solar light irradiation for $25 \mathrm{~min}$. This result indicates that the prepared CuS can not only degrade a single dye (e.g., MB, RhB), but can also degrade the mixed systems including different kinds of dyes. The photocatalytic activities of 3D hierarchical network structured CuS are also superior to those of other reported CuS catalysts, as presented in Table 1. All these results further indicate that the 3D hierarchical network structured CuS, with a high surface area, is an effective catalyst for the degradation of industrial wastewater. To 
confirm the mineralization degree of $\mathrm{MB}$ and $\mathrm{RhB}$ dyes, the TOC values were measured. In the process of reaction, most of the MB and RhB can be mineralized (as shown in Table S1 in Supplementary material), which indicates that the excellent photocatalytic activity of the CuS with a 3D hierarchical network structure.

(a)

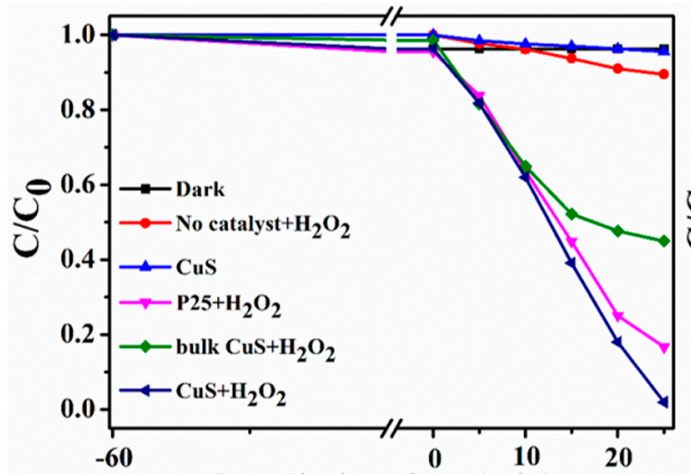

(c)

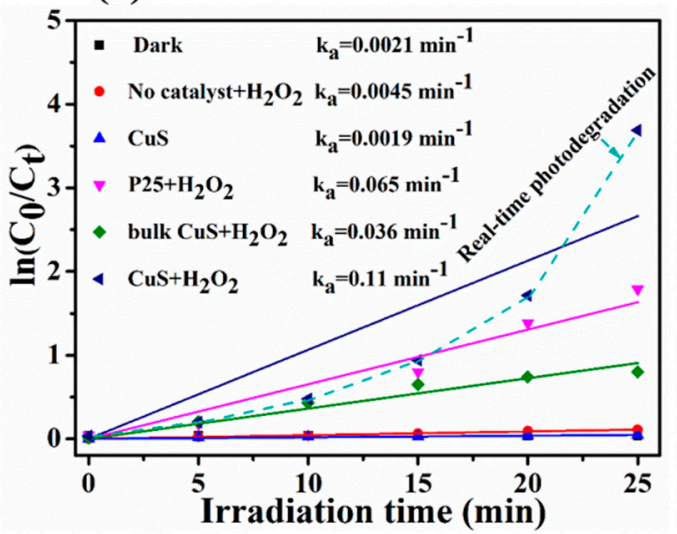

(b)

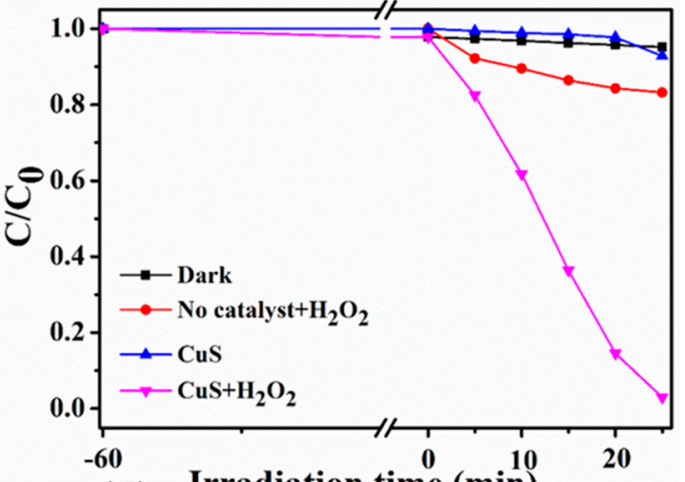

(d) Irradiation time (min)

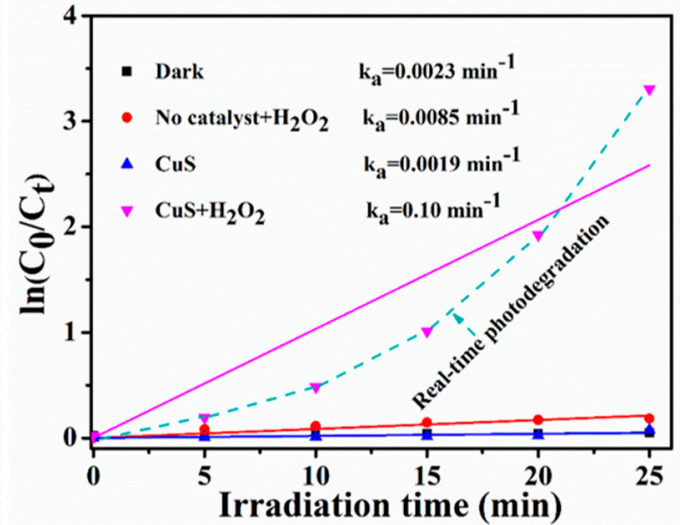

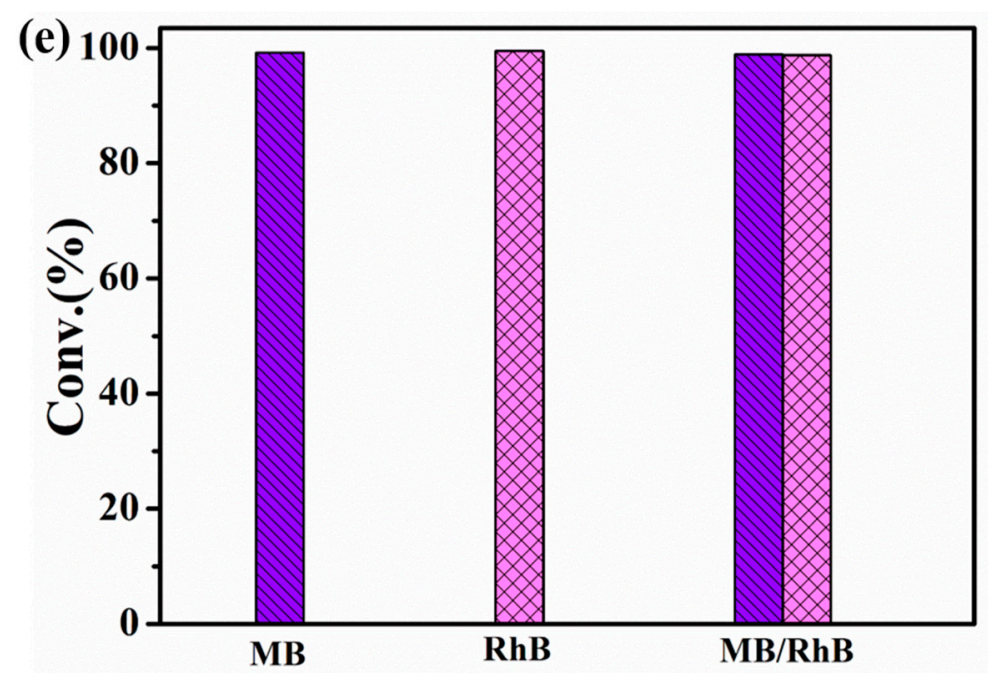

Figure 4. (a) Photocatalytic degradation of RhB and (b) MB under different conditions; (c) kinetics of RhB and (d) MB photocatalytic degradation over different catalysts; (e) simultaneous photocatalytic degradation of $\mathrm{MB}$ and $\mathrm{RhB}$ over $\mathrm{CuS}$ under identical experimental conditions (Reaction conditions: $0.05 \mathrm{~g}$ of photocatalyst, $40 \mathrm{~mL}$ of $10 \mathrm{mg} \mathrm{L}^{-1}$ dye solutions, $40 \mu \mathrm{L}$ of $\mathrm{H}_{2} \mathrm{O}_{2}, \mathrm{pH} 4,25 \mathrm{~min}$ of reaction time, $30{ }^{\circ} \mathrm{C}$.). 
Table 1. Photocatalytic activity data of different CuS catalysts for the degradation of different organic dyes.

\begin{tabular}{ccccc}
\hline Photocatalysts & Reaction Solution & Time (min) & $\begin{array}{c}\text { Photodegradation } \\
\text { Degree (\%) }\end{array}$ & Reference \\
\hline $\begin{array}{c}\text { CuS spherical } \\
\text { nanoflowers }\end{array}$ & $2.5 \mathrm{mg} \mathrm{L}^{-1} \mathrm{RhB}+1.5 \mathrm{~mL} \mathrm{H}_{2} \mathrm{O}_{2}$ & 30.0 & 90.0 & [45] \\
\hline $\begin{array}{c}\mathrm{CuS} \text { hierarchical } \\
\text { microflowers }\end{array}$ & $\begin{array}{c}12.0 \mathrm{mg} \mathrm{L}^{-1} \mathrm{RhB}+1.5 \mathrm{~mL} \mathrm{H}_{2} \mathrm{O}_{2} \\
12.0 \mathrm{mg} \mathrm{L}^{-1} \mathrm{MB}+1.5 \mathrm{~mL} \mathrm{H}_{2} \mathrm{O}_{2}\end{array}$ & $\begin{array}{l}55.0 \\
45.0\end{array}$ & $\begin{array}{l}95.0 \\
94.2\end{array}$ & {$[46]$} \\
\hline $\begin{array}{c}\mathrm{CuSh} \text { hierarchical } \\
\text { hollow microcubes }\end{array}$ & $10.0 \mathrm{mg} \mathrm{L}^{-1} \mathrm{MB}+1.3 \mathrm{~mL} \mathrm{H}_{2} \mathrm{O}_{2}$ & 30.0 & 95.9 & [47] \\
\hline $\begin{array}{c}\text { 3D hierarchical } \\
\text { CuS network }\end{array}$ & $10.0 \mathrm{mg} \mathrm{L}^{-1} \mathrm{RhB}+40.0 \mu \mathrm{L} \mathrm{H}_{2} \mathrm{O}_{2}$ & 25.0 & $\approx 100.0$ & This work \\
\hline
\end{tabular}

In addition, the cycling experiments were also conducted to investigate the photostability of the CuS catalyst. As shown in Figure 5, the catalyst can retain catalytic activities during the entire reaction process, without significant loss after four cycles. This result reveals that $\mathrm{CuS}$ with a stable 3D hierarchical network structure possesses a promising prospect as an ideal recyclable catalyst. Furthermore, the XRD results indicate that the crystal structure of CuS hardly changes before and after the catalytic reaction (see Figure 6).

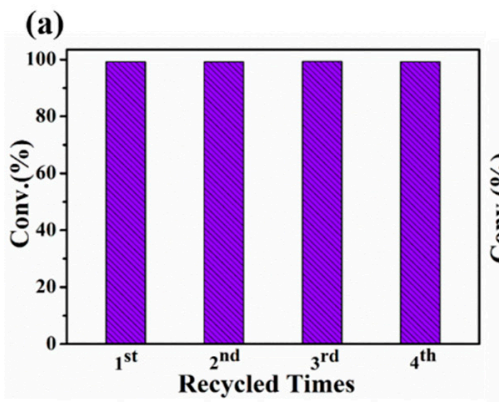

(b)

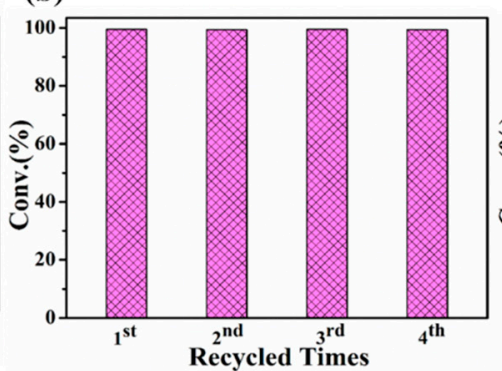

(c)

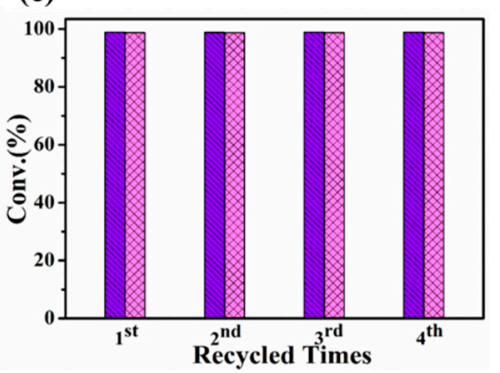

Figure 5. Cycling test on CuS for the photocatalytic degradation of (a) MB, (b) RhB, and (c) MB/RhB under simulated solar light irradiation.

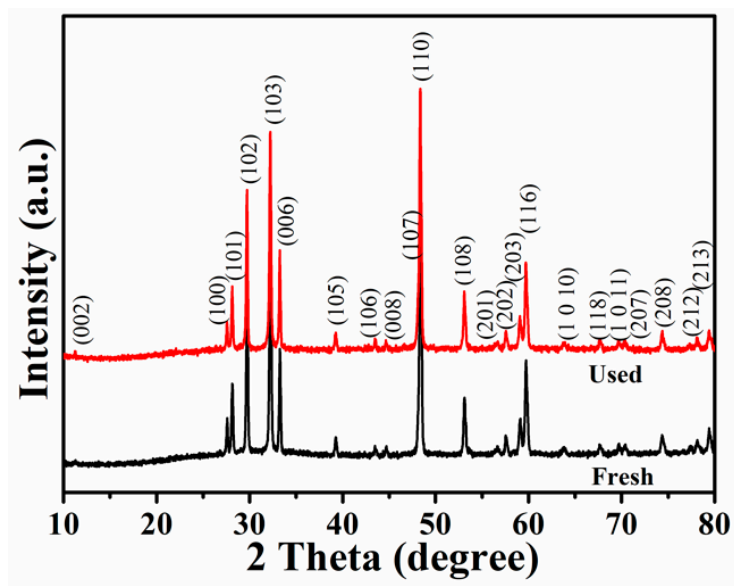

Figure 6. XRD patterns of the prepared CuS before and after the catalytic reaction.

Based on these experimental results, we tentatively propose a plausible mechanism for photocatalytic degradation of organic dyes over CuS under simulated solar light irradiation, in Figure 7. $\mathrm{CuS}$ with a 3D hierarchical structure has been demonstrated to be an efficient Fenton-like reagent [22]. When CuS is excited, the reaction of photo-generated electrons with $\mathrm{H}_{2} \mathrm{O}_{2}$ generates $\mathrm{OH}$. [48], enabling the direct oxidation of adsorbed organic dyes by photo-generated holes [49]. Moreover, the 3D 
hierarchical network structure of CuS favors the transmission of photo-generated electrons, which, in turn, facilitates the separation of the charge-carrier. Furthermore, the large surface area of a 3D hierarchical network structure of CuS might generate abundant catalytic sites because of improved contact and interaction between reactants and active sites. Therefore, the generation of abundant photo-generated holes and $\mathrm{OH}$. radicals is ascribed to the synergistic effects of the above-mentioned processes, which considerably improves the degradation efficiency of the CuS catalyst with a 3D hierarchical network structure.

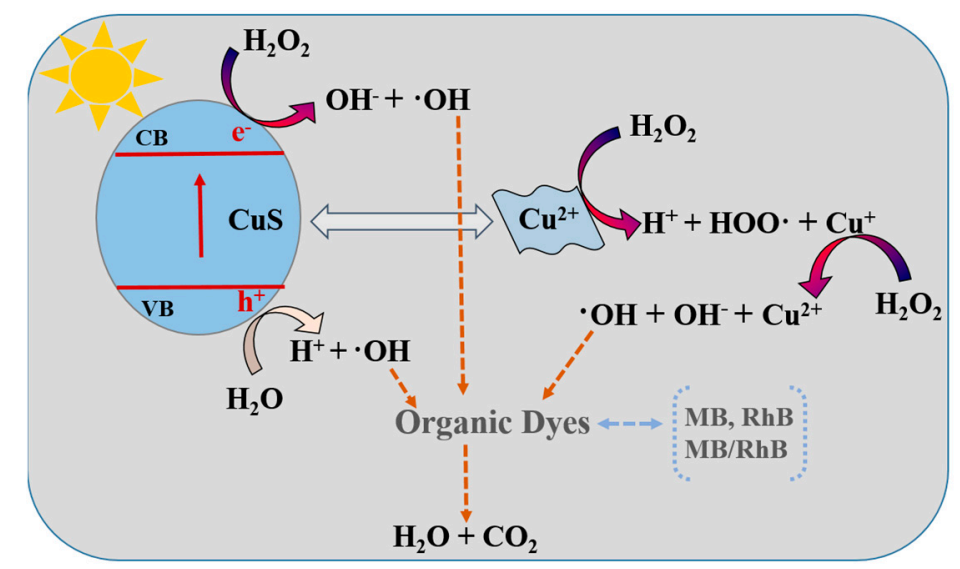

Figure 7. A plausible mechanism for the photocatalytic degradation of organic dyes over CuS under simulated solar light irradiation.

\section{Materials and Methods}

\subsection{Materials}

All materials and chemicals in this study were used directly without additional purification. Deionized water was acquired from local sources.

\subsection{Preparation of 3D Hierarchical CuS Catalysts}

The preparation of 3D hierarchical CuS catalysts was carried out via one-step heating sulfuration. Copper foam $(1 \mathrm{~cm} \times 1 \mathrm{~cm}, 1.5 \mathrm{mmol})$ and sulfur powder $(3.0 \mathrm{mmol})$ were heated at $400{ }^{\circ} \mathrm{C}$ under $\mathrm{N}_{2}$ atmosphere for $5 \mathrm{~h}$ to yield the 3D hierarchical CuS catalyst.

\subsection{Characterization}

X-ray diffraction (XRD) patterns were recorded on a Bruker D8 Advance X-ray powder diffractometer (Karlsruhe, Germany) using Ni-filtered $\mathrm{Cu} \mathrm{K} \alpha$ radiation. The whole solid was used for the XRD measurement. The optical property of the sample was determined using a UV-vis spectrophotometer (Perkin Elmer, Fremont, CA, USA). The Brunauer-Emmett-Teller (BET) surface areas and pore sizes of CuS samples were determined on the basis of nitrogen adsorption-desorption isotherms (Micromeritics Company, Norcross, GA, USA). X-ray photoelectron spectroscopy (XPS) measurements (Thermo Fisher Scientific, Waltham, MA, USA) were measured on an ESCALAB 250 photoelectron spectroscope, with a monochromatic Al K $\alpha$ source. The powder samples were used for the characterization measurements. The morphologies of the obtained samples were taken on a ZEISS SIGMA field emission scanning electron microscope (SEM) (Carl Zeiss Ltd., Welwyn Garden City, UK). Transmission electron microscopy (TEM) images were obtained using a FEI Tecnai G2 F30 electron microscope (FEI Company, Hillsboro, OR, USA). The total organic carbon (TOC) values were measured using a TOC-2000 apparatus (Shanghai, China). 


\subsection{Evaluation of Photocatalytic Activity}

To assess the photocatalytic performance of the catalysts, $\mathrm{MB}$ and $\mathrm{RhB}$ were used as the model organic dyes. Typically, the photocatalytic activity studies were conducted at $30^{\circ} \mathrm{C}$ in a $100 \mathrm{~mL}$ quartz reactor (Beijing, China) containing a prepared CuS sample and a dye solution $\left(10 \mathrm{mg} \mathrm{L}^{-1}, 40 \mathrm{~mL}\right)$ with one of the dyes: $\mathrm{MB}, \mathrm{RhB}$, or $\mathrm{MB} / \mathrm{RhB}$ (a mixed solution of $\mathrm{MB}$ and $\mathrm{RhB}$ ). $\mathrm{H}_{2} \mathrm{SO}_{4}(2 \mathrm{~mol} / \mathrm{L}$ ) was used to adjust the $\mathrm{pH}$ value of the reaction solution to $\mathrm{pH}=4$. After adding $40 \mu \mathrm{L}$ of $\mathrm{H}_{2} \mathrm{O}_{2}$, the reaction mixture was slowly stirred in the dark for $1 \mathrm{~h}$ to achieve the adsorption-desorption equilibrium. The suspension was then irradiated with a Xe lamp of 300 W (PLS-SXE 300, Beijing Perfect Light Co. Ltd., Beijing, China). During the reaction, about $3 \mathrm{~mL}$ of solution was taken out at an interval, and immediately used for the determination of the dye solution's concentration by using a UV-Vis spectrophotometer (Perkin Elmer, Fremont, CA, USA). When the reaction was complete, the collected sample was washed with water and ethanol successively several times. After it was thoroughly dried, the prepared sample was ready for use.

\section{Conclusions}

In summary, a simple, facile, and one-step in situ heating sulfuration strategy was developed to prepare the CuS photocatalyst with a 3D hierarchical network structure. The prepared CuS exhibits excellent photocatalytic and recyclable performance for the degradation of $\mathrm{MB}, \mathrm{RhB}$, and $\mathrm{MB} / \mathrm{RhB}$ dye solutions under simulated solar light irradiation. According to the results of this study, the excellent photocatalytic performance of fabricated CuS was attributed to its large surface area and abundant active sites. This work affords a novel and convenient method for the fabrication of CuS with a 3D hierarchical structure under mild conditions, as a highly efficient and recyclable photocatalyst.

Supplementary Materials: The following are available online at http://www.mdpi.com/2073-4344/10/1/40/s1, Figure S1: $\mathrm{N}_{2}$ adsorption-desorption isotherm and pore size (inset) of the as-prepared CuS, Figure S2: SEM image of the copper foam, Figure S3: (a) Control experiments for the degradation of RhB under different conditions; (b) Control experiments for the degradation of $\mathrm{MB}$ and $\mathrm{RhB}$ under different conditions, Table S1: Removal rate of TOC with the as-prepared CuS.

Author Contributions: Conceptualization, L.M.; conceived the experiments, N.Q. and W.W.; performed the major experiments and wrote the manuscript, N.Q.; performed a part of the measurements, W.W. and C.H. All authors have read and agreed to the published version of the manuscript.

Funding: This work was supported by the National Natural Science Foundation of China (Grant No. 21671205 and U1804126), Program for Interdisciplinary Direction Team in Zhongyuan University of Technology, the Collaborative Innovation Centre of Henan Textile and Clothing Industry, and the Innovation Scientists and Technicians Troop Construction Projects of Henan Province (Grant No. 164100510007 and CXTD2015018).

Conflicts of Interest: The authors declare no conflict of interest.

\section{References}

1. Lang, X.; Chen, X.; Zhao, J. Heterogeneous visible light photocatalysis for selective organic transformations. Chem. Soc. Rev. 2014, 43, 473-486. [CrossRef]

2. Andreozzi, R.; Caprio, V.; Insola, A.; Marotta, R. Advanced oxidation processes (AOP) for water purification and recovery. Catal. Today 1999, 53, 51-53. [CrossRef]

3. Li, X.; Huang, X.; Xi, S.; Miao, S.; Ding, J.; Cai, W.; Liu, S.; Yang, X.; Yang, H.; Gao, J.; et al. Single cobalt atoms anchored on porous $\mathrm{N}$-doped graphene with dual reaction sites for efficient fenton-like catalysis. J. Am. Chem. Soc. 2018, 140, 12469-12475. [CrossRef] [PubMed]

4. Chen, X.; Mao, S.S. Titanium dioxide nanomaterials: Synthesis, properties, modifications, and applications. Chem. Rev. 2007, 107, 2891-2959. [CrossRef]

5. Frank, S.N.; Bard, A.J. Heterogeneous photocatalytic oxidation of cyanide ion in aqueous solutions at titanium dioxide powder. J. Am. Chem. Soc. 1977, 99, 303-304. [CrossRef]

6. Li, H.; Zhang, X.; Huo, Y.; Zhu, J. Supercritical preparation of a highly active S-doped $\mathrm{TiO}_{2}$ photocatalyst for methylene blue mineralization. Environ. Sci. Technol. 2007, 41, 4410-4414. [CrossRef] [PubMed] 
7. Chen, C.; Ma, W.; Zhao, J. Semiconductor-mediated photodegradation of pollutants under visible-light irradiation. Chem. Soc. Rev. 2010, 39, 4206-4219. [CrossRef]

8. Liu, G.; Zhao, Y.; Sun, C.; Li, F.; Lu, G.; Cheng, H. Synergistic effects of B/N doping on the visible-light photocatalytic activity of mesoporous $\mathrm{TiO}_{2}$. Angew. Chem. Int. Ed. 2008, 47, 4516-4520. [CrossRef]

9. Liu, M.; Qiu, X.; Miyauchi, M.; Hashimoto, K. Cu(II) oxide amorphous nanoclusters grafted $\mathrm{Ti}^{3+}$ self-doped $\mathrm{TiO}_{2}$ : An efficient visible light photocatalyst. Chem. Mater. 2011, 23, 5282-5286. [CrossRef]

10. Zhao, D.; Chen, C.; Wang, Y.; Ma, W.; Zhao, J.; Rajh, T.; Zang, L. Enhanced photocatalytic degradation of dye pollutants under visible irradiation on $\mathrm{Al}(\mathrm{III})$-modified $\mathrm{TiO}_{2}$ : Structure, interaction, and interfacial electron transfer. Environ. Sci. Technol. 2007, 42, 308-314. [CrossRef]

11. Yu, J.; Xiang, Q.; Zhou, M. Preparation, characterization and visible-light-driven photocatalytic activity of Fe-doped titania nanorods and first-principles study for electronic structures. Appl. Catal. B: Environ. 2009, 90, 595-602. [CrossRef]

12. Qin, N.; Xiong, J.; Liang, R.; Liu, Y.; Zhang, S.; Li, Y.; Li, Z.; Wu, L. Highly efficient photocatalytic $\mathrm{H}_{2}$ evolution over $\mathrm{MoS}_{2} / \mathrm{CdS}-\mathrm{TiO}_{2}$ nanofibers prepared by an electrospinning mediated photodeposition method. Appl. Catal. B: Environ. 2017, 202, 374-380. [CrossRef]

13. Yin, X.-L.; Li, L.-L.; Jiang, W.-J.; Zhang, Y.; Zhang, X.; Wan, L.-J.; Hu, J.-S. MoS $2 /$ CdS nanosheets-on-nanorod heterostructure for highly efficient photocatalytic $\mathrm{H}_{2}$ generation under visible light irradiation. ACS Appl. Mater. Interfaces 2016, 8, 15258-15266. [CrossRef] [PubMed]

14. Khan, Z.; Khannam, M.; Vinothkumar, N.; De, M.; Qureshi, M. Hierarchical 3D NiO-CdS heteroarchitecture for efficient visible light photocatalytic hydrogen generation. J. Mater. Chem. 2012, 22, 12090-12095. [CrossRef]

15. Gogoi, G.; Keene, S.; Patra, A.S.; Sahu, T.K.; Ardo, S.; Qureshi, M. Hybrid of g- $\mathrm{C}_{3} \mathrm{~N}_{4}$ and $\mathrm{MoS}_{2}$ integrated onto $\mathrm{Cd}_{0.5} \mathrm{Zn}_{0.5} \mathrm{~S}$ : Rational design with efficient charge transfer for enhanced photocatalytic activity. ACS Sustain. Chem. Eng. 2018, 6, 6718-6729. [CrossRef]

16. Yin, X.; Liu, J.; Jiang, W.; Zhang, X.; Hu, J.; Wan, L. Urchin-Like Au@CdS/ $\mathrm{WO}_{3}$ Micro/Nano Heterostructure as a Visible-Light Driven Photocatalyst for Efficient Hydrogen Generation. Chem. Commun. 2015, 51, 13842-13845. [CrossRef] [PubMed]

17. Basu, M.; Sinha, A.K.; Pradhan, M.; Sarkar, S.; Negishi, Y.; Pal, T. Evolution of hierarchical hexagonal stacked plates of CuS from liquid-liquid interface and its photocatalytic application for oxidative degradation of different dyes under indoor lighting. Environ. Sci. Technol. 2010, 44, 6313-6318. [CrossRef] [PubMed]

18. Cheng, Z.; Wang, S.; Wang, Q.; Geng, B. A facile solution chemical route to self-assembly of CuS ball-flowers and their application as an efficient photocatalyst. CrystEngComm 2010, 12, 144-149. [CrossRef]

19. Tanveer, M.; Cao, C.; Ali, Z.; Aslam, I.; Idrees, F.; Khan, W.S.; But, F.K.; Tahir, M.; Mahmood, N. Template free synthesis of CuS nanosheet-based hierarchical microspheres: An efficient natural light driven photocatalyst. CrystEngComm 2014, 16, 5290-5300. [CrossRef]

20. Zhang, Y.; Tian, J.; Li, H.; Wang, L.; Qin, X.; Asiri, A.M.; Al-Youbi, A.O.; Sun, X. Biomolecule-assisted, environmentally friendly, one-pot synthesis of CuS/reduced graphene oxide nanocomposites with enhanced photocatalytic performance. Langmuir 2012, 28, 12893-12900. [CrossRef]

21. Li, Y.-H.; Qi, M.-Y.; Li, J.-Y.; Tang, Z.-R.; Xu, Y.-J. Noble metal free CdS@CuS-NixP hybrid with modulated charge transfer for enhanced photocatalytic performance. Appl. Catal. B: Environ. 2019, 257, 117934. [CrossRef]

22. Li, Z.; Mi, L.; Chen, W.; Hou, H.; Liu, C.; Wang, H.; Zheng, Z.; Shen, C. Three-dimensional CuS hierarchical architectures as recyclable catalysts for dye decolorization. CrystEngComm 2012, 14, 3965-3971. [CrossRef]

23. Sun, S.; Li, P.; Liang, S.; Yang, Z. Diversified copper sulfide $\left(\mathrm{Cu}_{2}-\mathrm{xS}\right)$ micro-/nanostructures: A comprehensive review on synthesis, modifications and applications. Nanoscale 2017, 9, 11357-11404. [CrossRef] [PubMed]

24. Wang, M.; Xie, F.; Li, W.; Chen, M.; Zhao, Y. Preparation of various kinds of copper sulfides in a facile way and the enhanced catalytic activity by visible light. J. Mater. Chem. A 2013, 1, 8616-8621. [CrossRef]

25. Zhao, L.; Zhou, L.; Sun, C.; Gu, Y.; Wen, W.; Fang, X. Rose-like CuS microflowers and their enhanced visible-light photocatalytic performance. CrystEngComm 2018, 20, 6529-6537. [CrossRef]

26. Zhang, F.; Jiang, Y.; Liu, X.; Meng, J.; Zhang, P.; Liu, H.; Yang, G.; Li, G.; Jiang, L.; Wan, L.-J.; et al. Hierarchical nanowire arrays as three-dimensional fractal nanobiointerfaces for high efficient capture of cancer cells. Nano Lett. 2016, 16, 766-772. [CrossRef] 
27. Yang, H.; Zhang, Y.; Hu, F.; Wang, Q. Urchin-like CoP nanocrystals as hydrogen evolution reaction and oxygen reduction reaction dual-electrocatalyst with superior stability. Nano Lett. 2015, 15, 7616-7620. [CrossRef]

28. Wei, W.; Ma, G.-H.; Hu, G.; Yu, D.; Mcleish, T.; Su, Z.-G.; Shen, Z.-Y. Preparation of hierarchical hollow $\mathrm{CaCO}_{3}$ particles and the application as anticancer drug carrier. J. Am. Chem. Soc. 2008, 130, 15808-15810. [CrossRef]

29. Shi, Y.; Zhu, C.; Wang, L.; Zhao, C.; Li, W.; Fung, K.K.; Ma, T.; Hagfeldt, A.; Wang, N. Ultrarapid sonochemical synthesis of $\mathrm{ZnO}$ hierarchical structures: From fundamental research to high efficiencies up to $6.42 \%$ for quasi-solid dye-sensitized solar cells. Chem. Mater. 2013, 25, 1000-1012. [CrossRef]

30. Wang, H.; Rogach, A.L. Hierarchical $\mathrm{SnO}_{2}$ nanostructures: Recent advances in design, synthesis, and applications. Chem. Mater. 2014, 26, 123-133. [CrossRef]

31. Zhang, X.; Yang, F.; Cui, S.; Wei, W.; Chen, W.; Mi, L. Consecutive reaction to construct hierarchical nanocrystalline CuS "branch" with tunable catalysis propertie. Sci. Rep. 2016, 6, 30604. [CrossRef] [PubMed]

32. Sun, K.; Jing, Y.; Park, N.; Li, C.; Bando, Y.; Wang, D. Solution synthesis of large-scale, high-sensitivity ZnO/Si hierarchical nanoheterostructure photodetectors. J. Am. Chem. Soc. 2010, 132, 15465-15467. [CrossRef] [PubMed]

33. Sheng, X.; He, D.; Yang, J.; Zhu, K.; Feng, X. Oriented assembled $\mathrm{TiO}_{2}$ hierarchical nanowire arrays with fast electron transport properties. Nano Lett. 2014, 14, 1848-1852. [CrossRef]

34. Nagarathinam, M.; Chen, J.; Vittal, J.J. From self-assembled Cu(II) coordination polymer to shape-controlled CuS nanocrystals. Cryst. Growth Des. 2009, 9, 2457-2463. [CrossRef]

35. Zhu, H.; Wang, J.; Wu, D. Fast synthesis, formation mechanism, and control of shell thickness of CuS hollow spheres. Inorg. Chem. 2009, 48, 7099-7104. [CrossRef]

36. Kundu, J.; Pradhan, D. Controlled synthesis and catalytic activity of copper sulfide nanostructured assemblies with different morphologies. ACS Appl. Mater. Interfaces 2014, 6, 1823-1834. [CrossRef]

37. Zhang, Y.; Yao, L.; Zhang, G.; Dionysiou, D.D.; Li, J.; Du, X. One-step hydrothermal synthesis of high-performance visible-light-driven $\mathrm{SnS}_{2} / \mathrm{SnO}_{2}$ nanoheterojunction photocatalyst for the reduction of aqueous Cr (VI). Appl. Catal. B: Environ. 2014, 144, 730-738. [CrossRef]

38. Xu, X.; Lu, R.; Zhao, X.; Zhu, Y.; Xu, S.; Zhang, F. Novel mesoporous $\mathrm{Zn}_{\mathrm{x}} \mathrm{Cd}_{1-\mathrm{x}} \mathrm{S}$ nanoparticles as highly efficient photocatalysts. Appl. Catal. B: Environ. 2012, 125, 11-20. [CrossRef]

39. Ghijsen, J.; Tjeng, L.H.; van Elp, J.; Eskes, H.; Westerink, J.; Sawatzky, G.A.; Czyzyk, M.T. Electronic structure of $\mathrm{Cu}_{2} \mathrm{O}$ and CuO. Phys. Rev. B 1988, 38, 11322-11330. [CrossRef]

40. Yu, J.; Zhang, J.; Liu, S. Ion-exchange synthesis and enhanced visible-light photoactivity of CuS/ZnS nanocomposite hollow spheres. J. Phys. Chem. C 2010, 114, 13642-13649. [CrossRef]

41. Song, C.; Wang, X.; Zhang, J.; Chen, X.; Li, C. Enhanced performance of direct Z-scheme CuS-WO 3 system towards photocatalytic decomposition of organic pollutants under visible light. Appl. Surf. Sci. 2017, 425, 788-795. [CrossRef]

42. Zhang, J.; Yu, J.; Zhang, Y.; Li, Q.; Gong, J. Visible light photocatalytic $\mathrm{H}_{2}$-production activity of CuS/ZnS porous nanosheets based on photoinduced interfacial charge transfer. Nano Lett. 2011, 11, 4774-4779. [CrossRef]

43. Shu, Q.; Lan, J.; Gao, M.; Wang, J.; Huang, C. Controlled synthesis of CuS caved superstructures and their application to the catalysis of organic dye degradation in the absence of light. CrystEngComm 2015, 17, 1374-1380. [CrossRef]

44. Wang, X.; He, Y.; Hu, Y.; Jin, G.; Jiang, B.; Huang, Y. Photothermal-conversion-enhanced photocatalytic activity of flower-like CuS superparticles under solar light irradiation. Sol. Energy 2018, 170, 586-593. [CrossRef]

45. Zhang, Y.-Q.; Zhang, B.-P.; Ge, Z.-H.; Zhu, L.-F.; Li, Y. Preparation by solvothermal synthesis, growth mechanism, and photocatalytic performance of CuS nanopowders. Eur. J. Inorg. Chem. 2014, 2014, 2368-2375. [CrossRef]

46. Tanveer, M.; Cao, C.; Aslam, I.; Ali, Z.; Idrees, F.; Khan, W.S.; Tahir, M.; Khalid, S.; Nabi, G.; Mahmood, A. Synthesis of CuS flowers exhibiting versatile photocatalyst response. New J. Chem. 2015, 39, 1459-1468. [CrossRef]

47. Cai, L.; Sun, Y.; Li, W.; Zhang, W.; Liu, X.; Ding, D.; Xu, N. CuS hierarchical hollow microcubes with improved visible-light photocatalytic performance. RSC Adv. 2015, 5, 98136-98143. [CrossRef] 
48. Ghosh, A.; Mondal, A. A simple electrochemical route to deposit $\mathrm{Cu}_{7} \mathrm{~S}_{4}$ thin films and their photocatalytic properties. Appl. Surf. Sci. 2015, 328, 63-70. [CrossRef]

49. Más, A.A.; Wei, D. Photoelectrochemical properties of graphene and its derivatives. Nanomaterials 2013, 3, 325-356. article distributed under the terms and conditions of the Creative Commons Attribution (CC BY) license (http://creativecommons.org/licenses/by/4.0/). 